\title{
NEW MANIPULATOR CONCEPT FOR HANDLING TASKS IN COAL-MINING
}

\author{
J. Harzer \\ Ruhrkohle Westfalen AG, WD Heinrich-Robert \\ W. Engeln \\ Fraunhofer-Institut für Produktionstechnik und Automatisierung (IPA) Stuttgart
}

\section{$\underline{\text { Summary }}$}

This paper describes a new manipulator concept for application in underground coalmining. The manipulator was developed to set support elements in drifting. Experience with a first prototype and the demands for further development of the manipulator are outlined. Furthermore, this paper contains a short description of the control concept planned for the manipulator.

Despite of a high degree of mechanization in german coal-mining, a considerable amount of physical activities of the coal-miners are physically highly strainfull and risky. To reduce strains and risks, further automation is necessary. Another objective is the reduction of costs.

One of the fields producing high costs with high physical strains for the coal-miners is roadway-timbering / $1 /$. Especially for this field, different automatization concepts are available $/ 2 \%$. The key element of these automatization concepts is a workingplatform with an integrated manipulator arm. With such an arm it is possible to set 
one or more crown-elements. Setting side-elements is not possible with such a concept.

The outlined new manipulator concept was developed in close cooperation between the german Ruhrkohle AG and IPA-Stuttgart.

The manipulator is being developed for setting crown- and side-elements in drifting. It is designed to cooperate with a working platform. Main handling tasks of the manipulator are:

- loading the working platform with support elements,

- picking-up of the crown-elements from the working platform and setting of the crown-elements,

- picking-up of the side-elements from the working platform and setting of the sideelements.

$3 \quad$ Manipulator for the handling of support elements

The handling tasks described above require a completely new manipulator concept /3/. Objective was to design a compact manipulator with a minimum of required infrastructure and an essentially improved ratio of payload to weight of the manipulator.

\section{$\underline{3.1 \quad \text { Manipulator concept }}$}

Figure 1 shows a possible kinematic structure of a manipulator for setting roadway support elements in coal-mining. The basic idea of the concept was to use the last placed support element as fixpoint for the manipulator. Therefore, the manipulator has two identical grippers. Each gripper can be used as manipulator base as well as 
for handling of support elements. With one gripper the manipulator attaches itself at a support element.

For the necessary mobility the manipulator consists of six axes, one translatory and five rotatory axes.

The setting of support elements with such a manipulator is shown in figure 2 and figure 3. Each element, crown- or side-element, is placed by a separate manipulator. The kinematic of the manipulator allows movements of the manipulator along the support. This is realized by repeating the setting movements, figure 4 . The manipulator clings its free gripper at the next support element and opens the other gripper. With this free gripper, the manipulator now clings itself at the next support element.

To test the described manipulator concept, a prototype was build. An objective of the test was to check the possiblity to realize such a manipulator and the possiblity to cling the manipulator to a support element and to manipulate another support element.

Figure 5 shows the basic design of the manipulator prototype. The kinematic structure is the same as shown in figure 1.

The maximum reach is $0.8 \mathrm{~m}$ and the maximum payload $120 \mathrm{~kg}$. Axes number 3 and 4 of the prototype were equipped with hydraulic actuators, the other axes were equipped with hydraulic brakes only. Hydraulic actuators were used, because of the very high energy density of such actuators. This was absolutely necessary to realize the manipulator. The energy density of such a manipulator has to be substantially higher than of a normal industrial robot equipped with eletrical drives.

The grippers were custom-designed for this manipulator. They allowed to attach the manipulator to a support element without encompassing it.

Taking into account the safety aspect of the coal-mining, it was necessary to use steel for building up the manipulator.

For controlling the prototye of the manipulator, manual hydraulic valves were used. With these valves it was possible to control the actuators and to open or close the hydraulic breaks.

Figure 6 shows the first prototype of the manipulator. 
The results of the test with the prototype were:

- Safe gripping and manipulation of support elements with a weight of $120 \mathrm{~kg}$ is possible.

- The last assembled support can be used as fixpoint for the manipulator.

- It is possible to move the manipulator along the drift by repeating certain movements.

Disadvantages of the prototype were:

- The manipulator reach is too short. It is impossible to place or pick up support elements on the working platform.

- All axes require hydraulic actuators.

- The simultaneous coordination of the movements of six axes is impossible for human operators. Therefore, a robot controller is necessary.

$4 \quad$ Modifications of the kinematic structure

The experience drawn from the prototype test showed the necessity to increase the maximum reach of the manipulator and the maximum payload up to $150 \mathrm{~kg}$. Therefore it was necessary to modify the kinematic structure of the manipulator. The translatory axis will be replaced by a rotatory axis and the plane of rotation of the axes number 3 and 5 will be changed. With these modifications it is possible to increase the reach of the manipulator substantially.

Figure 7 shows the modified kinematic structure of the manipulator.

\subsection{Evaluation of the optimum design}

The investigation of the optimum length of the manipulator arms and the necessary pivoting angles was performed by using a software tool. With this tool an optimum design of the manipulator was found taking the demands from the handling task into account. 
With the specified new manipulator it will be possible to grip support elements directly form the floor or a working platform. Furthermore the investigation showed that it is necessary to move the base of the manipulator between setting crownelements and side-elements.

For the control of the manipulator, the experience gained from the prototype showed the absolute necessity to support the operator by a robot controller.

Different control concepts are possible. Figure 8 shows the effort to arrange handling systems as a function of the degree of automation and flexibility. For the proposed manipulator, the concept of a highly flexible handling system will be used. The main features of this concept are:

- Automatic repeatability of prescribed movements.

- Overdrive of the automatic movements by the operator.

- Difficult movements can be controlled manually in a world coordinate system. The transformation of coordinates and the control of each axis will be performed by the robot controller.

This control concept allows flexible use of the manipulator, especially in unstructured environment.

For the realization of such a control concept a powerful controller is necessary. Controllers used for other applications in underground are not powerful enough for this task. Due to the special safety aspects for electronic equipment in coal-mining it is necessary to develop a new controller for this application or to use a controller hardware for an industrial robot in a strong housing. The new type of manipulator kinematic demands new custom-designed software. In addition it is necessary to use sensors with a high resolution that fulfil the safety aspects too. 
The described manipulator concept was developed for the task of setting support elements in drifting. However, the concept of almost unconstrained choice of the manipulator fixpoint widens its operational range in the underground. Examples of different operational ranges are:

- material handling,

- installation of pipes,

- rebuilding of the standard support in a gate-end distribution box.

Furthermore, there are additional application fields in different branches of industry, for example in construction industry.

$7 \quad$ Outlook

Further steps in this project will be the design and realization of a second prototype with larger reach. This manipulator will be connected to a robot controller to employ it as a highly flexible handling system. It is planned to test this prototype in the underground of a coal-mine of the german Ruhrkohle AG. 


\section{REFERENCES}

/1/ Reiff, W.

Mechanisierung der Ausbauarbeiten im Spreng- und maschinellen Vortrieb

Bergbau 9 (1985)

S. 408 - 418

12/ Wanner, M.C.; Hofmann, R.

Manipulatoren für den Tunnel- und Streckenausbau im Untertagebetrieb Robotersysteme 3 (1987)

S. $237-245$

/3/ Harzer, J.; Vollmer, M.; Engeln, W.; Wanner, M.C.

Entwicklung eines Manipulators für den Streckenausbau im

Steinkohlebergbau

Robotersysteme 5 (1989)

S. $229-232$

/4/ Wanner, M.C.; Baumeister, K.; Köhler, G.W.; Walze, H.

Hochflexible Handhabungssysteme

Ergebnisse einer Einsatzfallstudie

Robotersystem 2 (1986)

S. $217-224$ 


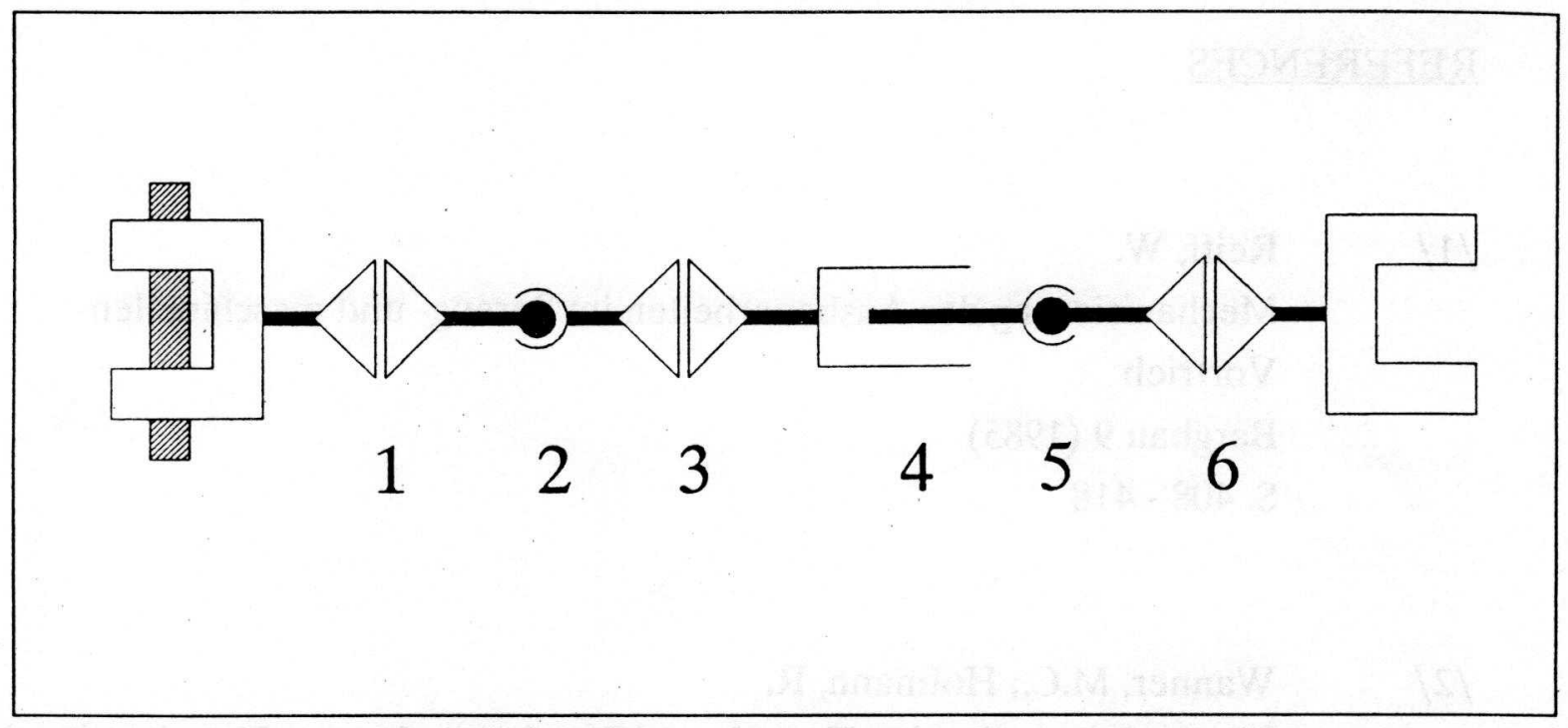

Figure 1: Kinematic struture of a manipulator for handling support elements in coal-mining

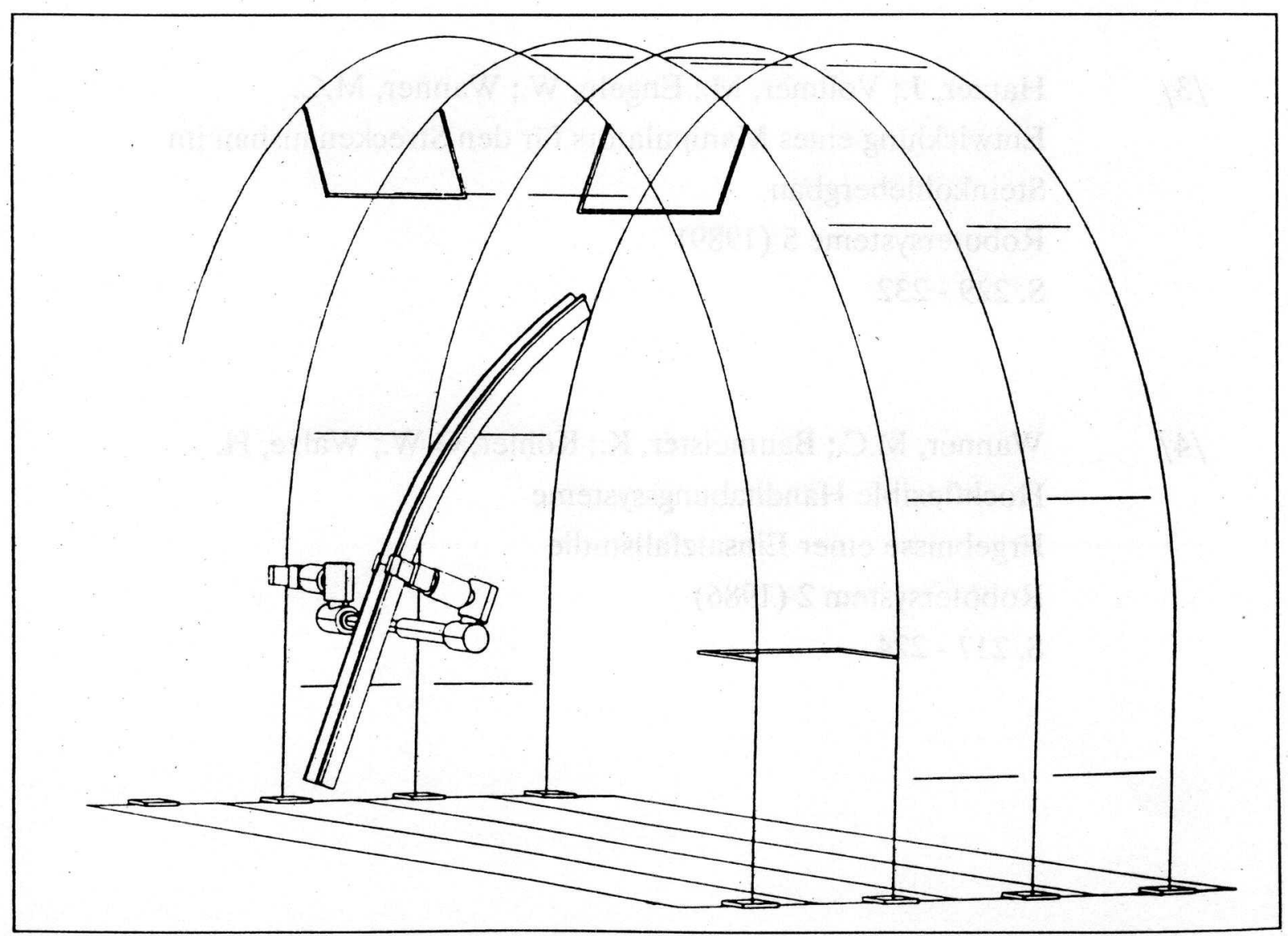

Figure 2: Set of a side-section with the manipulator 


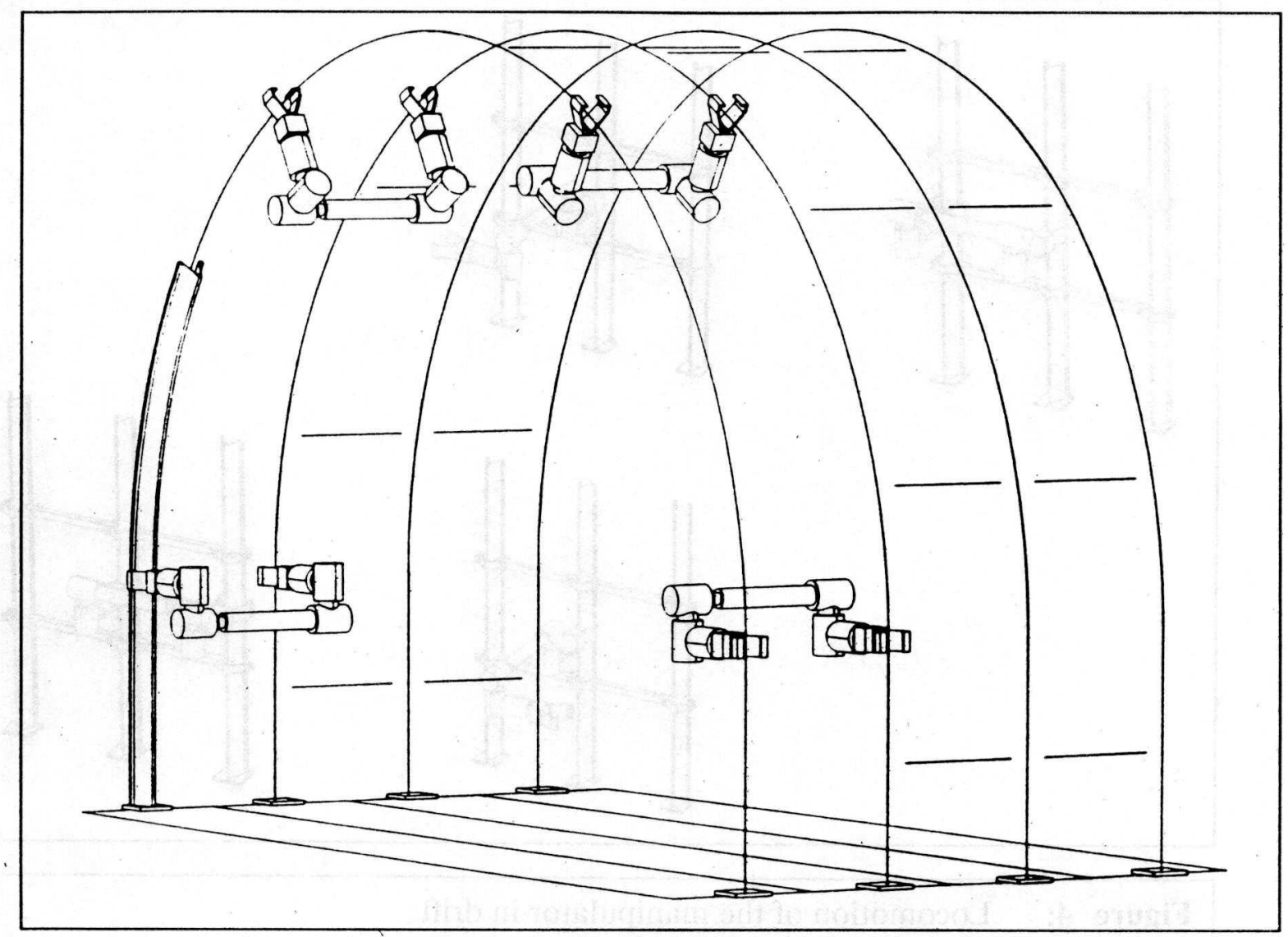

Figure 3: Set of a four section roadway-arc with four manipulators 

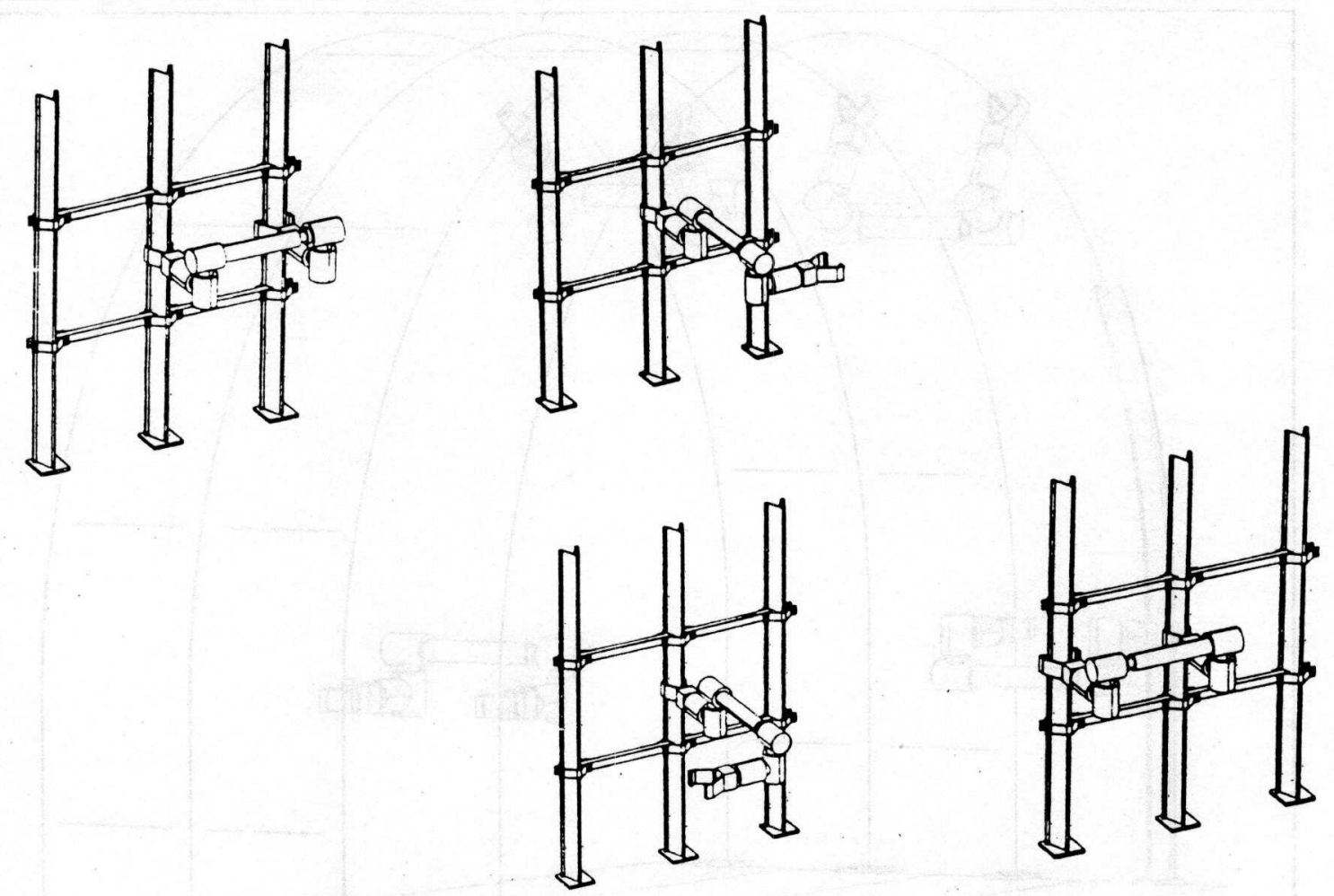

Figure 4: Locomotion of the manipulator in drift

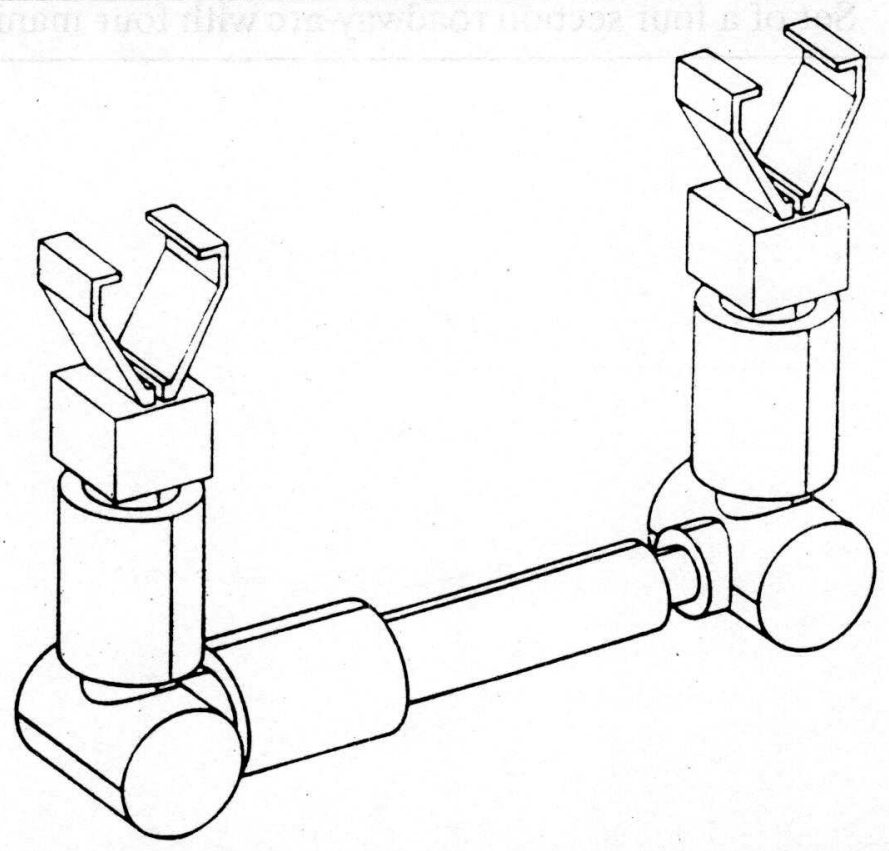

Figure 5: Basic design of the prototype 


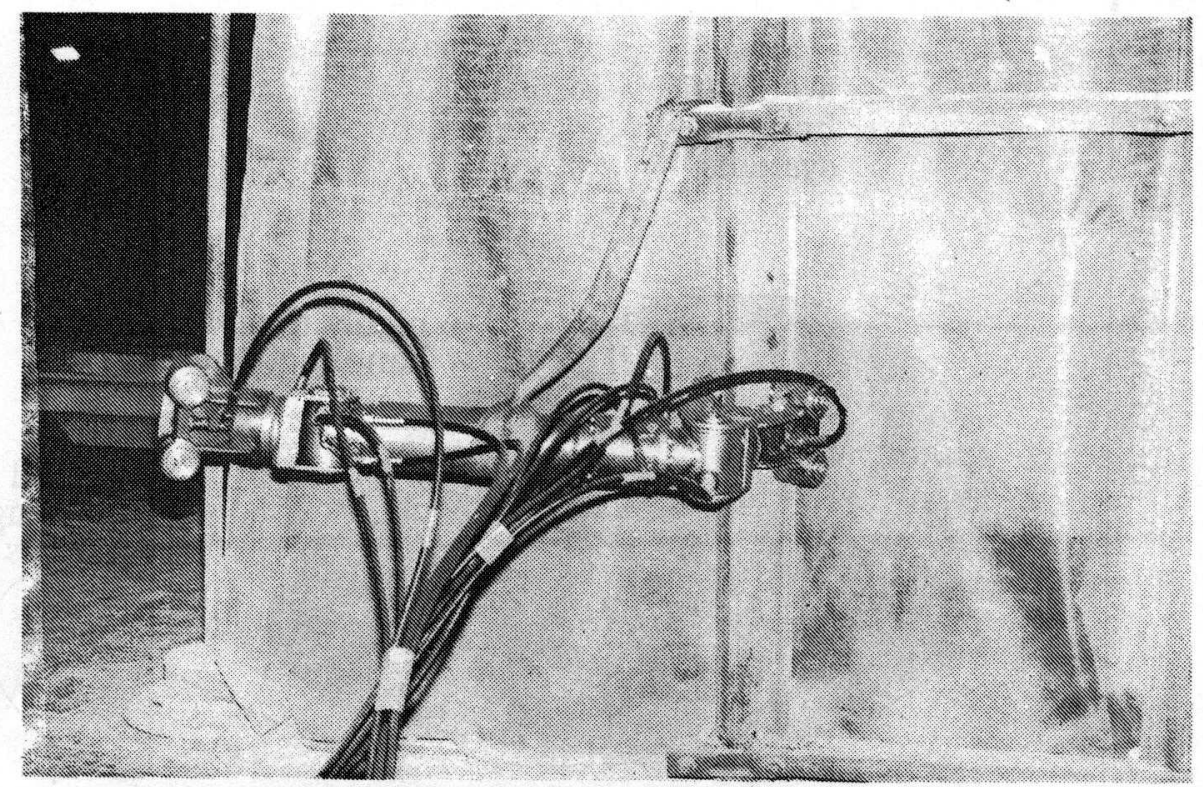

Figure 6: Prototype of the manipulator

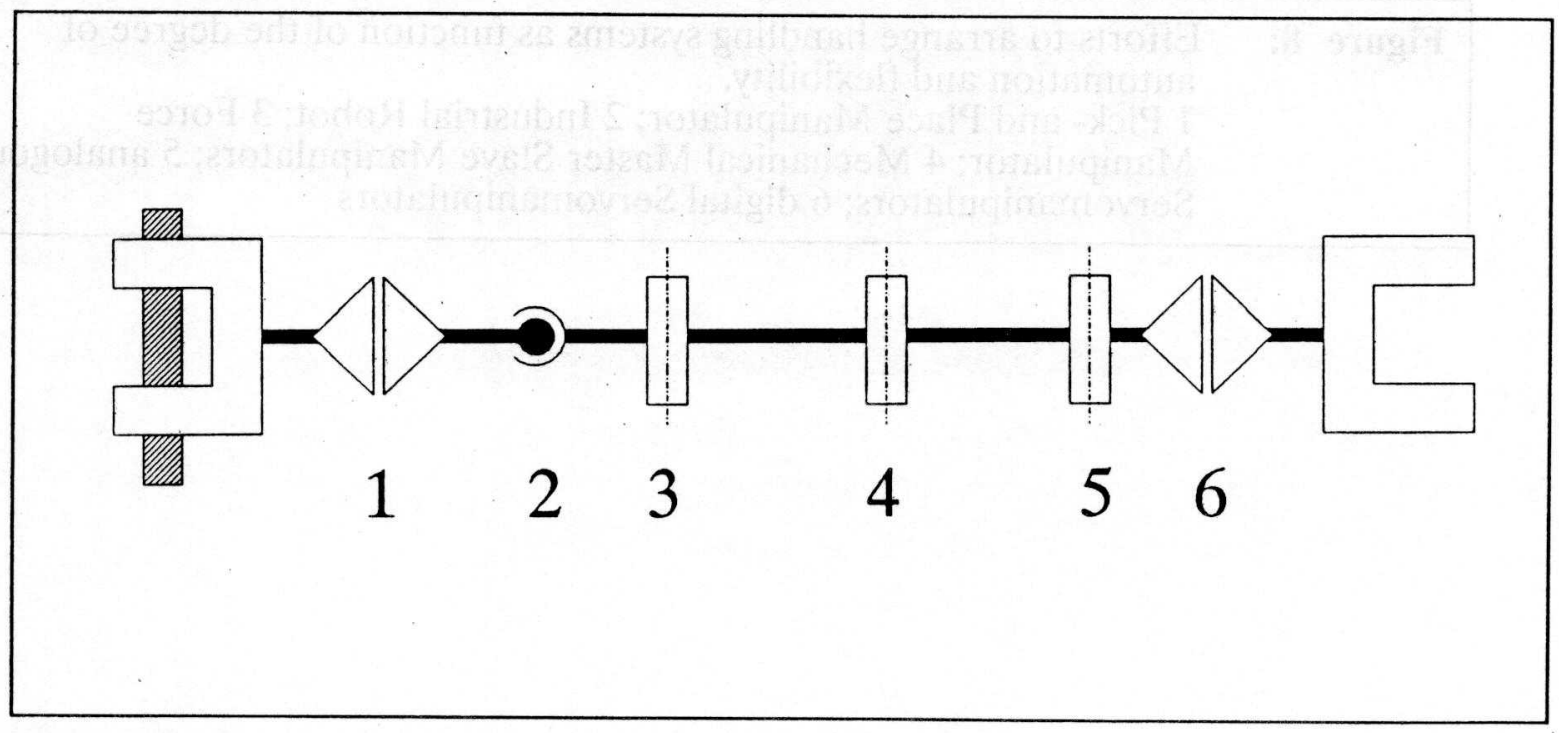

Figure 7: Kinematic structure of the redesigned manipulator 


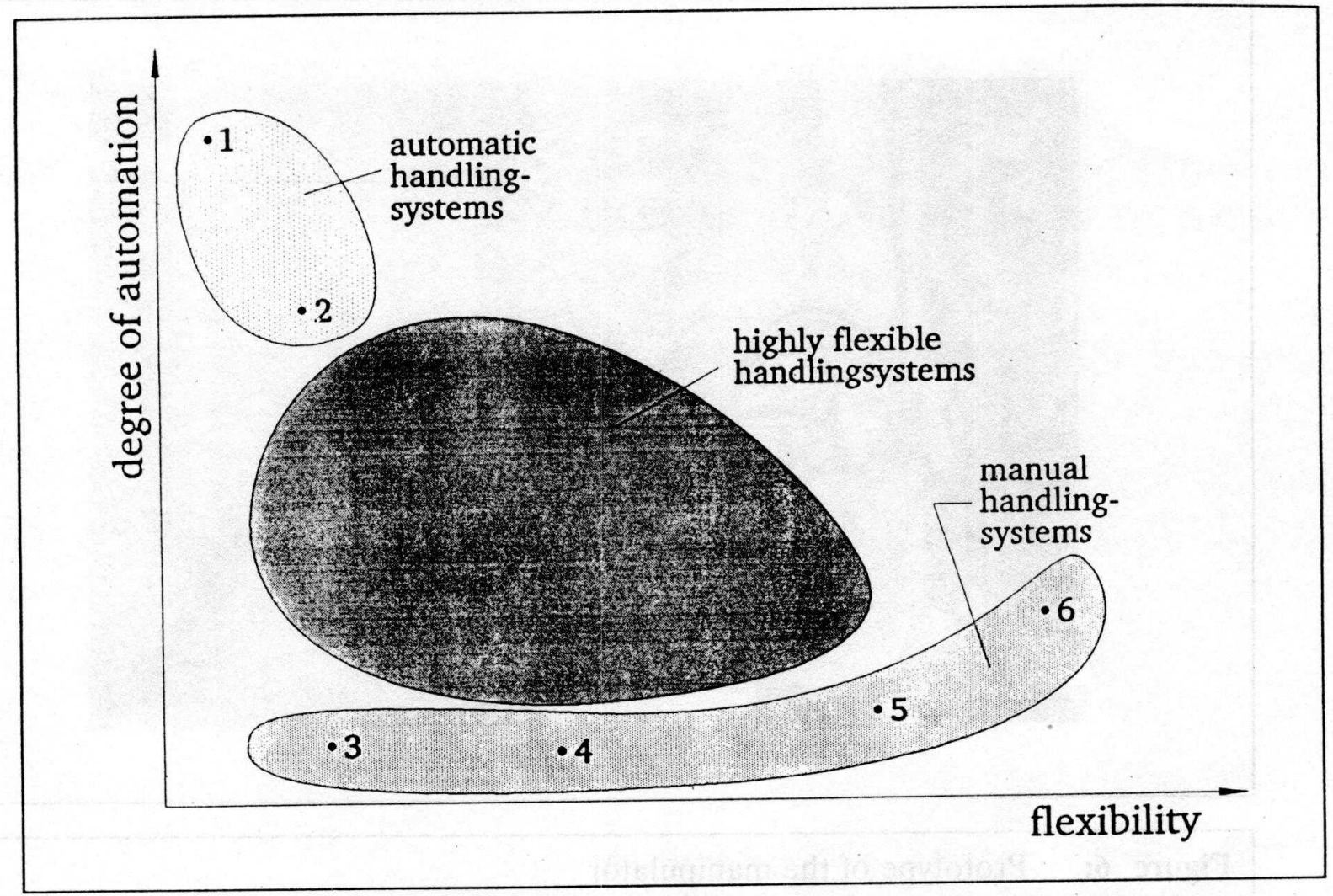

Figure 8: Efforts to arrange handling systems as function of the degree of automation and flexibility.

1 Pick- and Place Manipulator; 2 Industrial Robot; 3 Force

Manipulator; 4 Mechanical Master Slave Manipulators; 5 analogous

Servomanipulators; 6 digital Servomanipulators 